\title{
Intermedin promotes hepatocellular carcinoma cell proliferation through the classical Wnt signaling pathway
}

\author{
HAI SHANG, ZHI QIANG HAO, XI BO FU, XIANG DONG HUA, ZUO HONG MA, \\ FU LU AI, ZHAO QIANG FENG, KUN WANG, WEN XIN LI and BO LI
}

\author{
Department of Hepatobiliary Surgery, Liaoning Cancer Hospital and Institute, Shenyang, Liaoning 110042, P.R. China
}

Received September 22, 2015; Accepted March 24, 2017

DOI: $10.3892 / \mathrm{ol} .2018 .8033$

\begin{abstract}
The proliferative activity of hepatic carcinoma cells is directly associated with tumorigenesis, tumor development, metastasis and invasion. A variety of cytokines and peptides serve important roles in the development of hepatic carcinoma. The aim of the present study was to examine the effect of intermedin (IMD) on hepatic carcinoma cell proliferation and its mechanism of action. HepG2 hepatic carcinoma cell lines were treated with human recombinant IMD1-53 and its receptor antagonist IMD17-47. Cell proliferation was detected using a Cell Counting kit-8. The activation of the classical Wnt signaling pathway was demonstrated by the ratio of TOPflash:FOPflash luciferase activity. The expression of $c-M y c$ and $c y c l i n$ Dl downstream of the Wnt signaling pathway were detected using reverse transcription-quantitative polymerase chain reaction analysis. It was demonstrated that IMD may promote the proliferation of HepG2 cells in a time-dependent manner, and that the IMD receptor antagonist IMD17-47 could eliminate this promotion. IMD may activate classical Wnt signaling pathway transcriptional activity and the mRNA levels of certain downstream target genes. Furthermore, blocking of the Wnt signaling pathway may inhibit IMD-induced HepG2 cell proliferation to a certain extent. IMD may promote hepatic carcinoma cell proliferation by binding with receptor antagonist IMD17-47 and activating the Wnt signaling cascade, thus providing a novel avenue for the treatment of hepatic carcinoma.
\end{abstract}

Correspondence to: Dr Xiang Dong Hua, Department of Hepatobiliary Surgery, Liaoning Cancer Hospital and Institute, 44 Xiaoheyan Road, Dadong, Shenyang, Liaoning 110042, P.R. China

E-mail: xiangdonghua021@163.com

Abbreviations: IMD, intermedin; HCC, primary hepatocellular carcinoma

Key words: intermedin, hepatic carcinoma, proliferation, Wnt signaling pathway

\section{Introduction}

Primary hepatocellular carcinoma (HCC) is the most common type of malignant tumor worldwide, an incidence ranked third-highest of all types of cancer, a high degree of malignancy and a five-year survival rate of $30 \%$ (1). To date, no effective treatments have been developed (2). HCC is commonly diagnosed numerous countries with a high incidence of viral hepatitis (3). HCC contributes $85-90 \%$ of all primary liver cancers, with 500,000 new cases and 250,000 HCC-associated mortalities occurring worldwide every year (4). The main reasons for the high mortality rate of HCC patients are ascribed to the lack of effective treatments and the increasing resistance to conventional radiotherapy and chemotherapy (5). The proliferation of hepatoma cells is closely associated with HCC occurrence, development, invasion and metastasis (1). Small molecule bioactive peptides have various unique biological characteristics, including simple structures, extensive tissue distribution and a range of biological effects, which serve important roles in the regulation of the human metabolism and physiological function (6). A number of cytokines and small peptides have essential roles in the development of liver cancer. Intermedin (IMD) belongs to the calcitonin gene-related peptide (CGRP) superfamily (7). It was initially identified in teleost fish in 2004, and has also been identified in cDNA clones of other species, such as rodents and primates (8). IMD is widely distributed in the body, and its expression levels in adrenocortical tumors (9) and colorectal cancer (10) are high compared with those in normal tissues. IMD may also promote angiogenesis (11), suggesting that it is associated with the occurrence and development of tumors. The present study explored the effect of IMD in HCC and its underlying molecular mechanisms.

\section{Materials and methods}

HepG2 cells were purchased from Shanghai Bogoo Biological Technology Co., Ltd. (Shanghai, China), recombinant human IMD1-53 and its receptor antagonist (IMD17-47) were purchased from Phoenix Pharmaceuticals, Inc. (Burlingame, CA, USA). The Cell Counting Kit-8 (CCK-8) was purchased from Dojindo Molecular Technologies, Inc. (Kumamoto, Japan). The RNA extraction, reverse transcription (RT. kit and Luciferase reporter gene assay kit were purchased from 
Promega Corporation (Madison, WI, USA). The Taq enzyme was purchased from Tiangen Biotech Co., Ltd. (Beijing, China. and the fluorescent EvaGreen ${ }^{\circledR}$ Dye was purchased from Biotium, Inc. (Fremont, CA, USA). The classical Wnt pathway inhibitor (IWR-1-endo. was purchased from Cayman Chemical (Ann Arbour, MI, USA), the TOPflash/FOPflash plasmids for Wnt signaling pathway activity detection were purchased from Merck KGaA (Darmstadt, Germany) and the jetPEI ${ }^{\circledR}$ transfection reagent was purchased from Polyplus-Transfection SA (Illkirch, France).

Cell proliferation was detected using CCK-8. HepG2 cells in the logarithmic growth phase were inoculated in flat-bottomed 96-well plates at a density of $1 \times 10^{4} / 100$ cells $/ \mu 1$, and cultured in $5 \% \mathrm{CO}_{2}$ incubator at $37^{\circ} \mathrm{C}$. After $12 \mathrm{~h}$, the medium was replaced with fresh culture medium (Shanghai Yuan Long Biology Technology Company. containing various concentrations $(0,1,5,10,50$ and $100 \mathrm{nM}$. of IMD1-53, or with $100 \mathrm{nM}$ IMD17-47 and 25 nM IWR-1-endo. The complete culture medium without IMD and RPMI-1640 was used as the control. A total of $48 \mathrm{~h}$ after inoculation, $10 \mu \mathrm{l} \mathrm{CCK}-8$ was added into each well of the plate and placed in a $37^{\circ} \mathrm{C}$ incubator for $1-4 \mathrm{~h}$. A microplate reader was then used to measure the absorbance value at a wavelength of $450 \mathrm{~nm}$, as previously described (12).

RNA extraction. TRIzol ${ }^{\circledR}$ reagent (Promega Corporation) was used; the cells were aspirated from the culture medium and washed with PBS, following which $1 \mathrm{ml}$ RNAtrip reagent (Tideradar Beijing Technology Co., Ltd., Beijing, China. was added. The cells were triturated 30 times, transferred into an Eppendorf (EP) tube and placed at room temperature for $10 \mathrm{~min}$. A total of $0.2 \mathrm{ml}$ chloroform was added, reversal agiation was performed for $15 \mathrm{sec}$ and the samples were then incubated at room temperature for $5 \mathrm{~min}$. The samples were centrifuged at $12,000 \mathrm{x}$ for $15 \mathrm{~min}$ at $4^{\circ} \mathrm{C}$, and the resulting upper aqueous phase was carefully aspirated and transferred to a clean EP tube. Subsequently, an equal volume of isopropanol was added and mixed. The samples were allowed to precipitate for $2 \mathrm{~h}$ at $-70^{\circ} \mathrm{C}$, prior to being centrifuged at $12,000 \mathrm{x} \mathrm{g}$ for $10 \mathrm{~min}$ at $4^{\circ} \mathrm{C}$. The supernatant was discarded, and the cells were precipitated and washed with $1 \mathrm{ml} 0.75 \mathrm{X}$ ice-cold ethanol. They were then centrifuged again at 12,000 x g and $4^{\circ} \mathrm{C}$ for $10 \mathrm{~min}$, following which the supernatant was discarded. When the whitish pattern appeared in the center, the RNA enzyme pure water 50-100 $\mu \mathrm{l}$ was added, and quantified with a spectrophotometer.

Reversetranscription-quantitativepolymerasechainreaction $(R T-q P C R)$. The reverse transcription reaction involved a $20 \mu 1$ reaction system 5-(and-6)-carboxy-2',7'-dichlorofluorescein ( $\mathrm{pH}$ 9.0; purchased from Beijing Jiamei Nuonuo Biological Technology Co., Ltd.), with $2 \mu \mathrm{g}$ RNA (protector RNase inhibitor) starting, and used a reverse transcription kit according to the manufacturer's protocol (purchased from Promega Corporation) for first strand cDNA synthesis. RT-qPCR (Shanghai Solarbio Biological Technology Co., Ltd.. involved a $25 \mu 1$ reaction system, and $1 \mu 1$ reverse transcription reaction mixture was used as a template. Amplification conditions were as follows: Pre-degeneration for $5 \mathrm{~min}$ at $94^{\circ} \mathrm{C}$, degeneration for $30 \mathrm{sec}$ at $94^{\circ} \mathrm{C}$, annealing

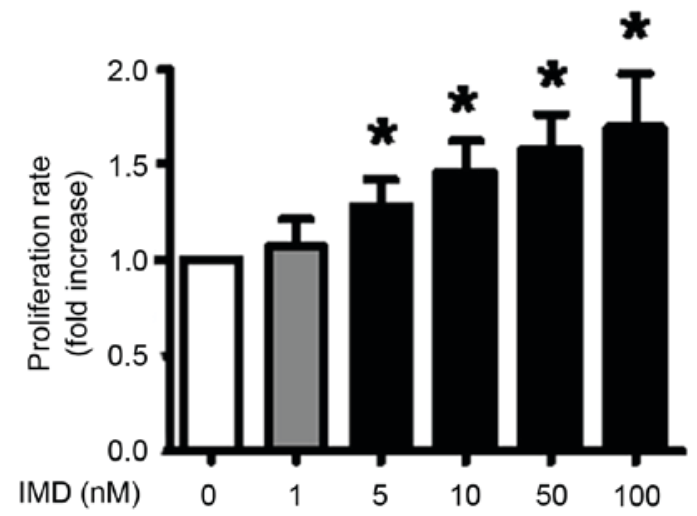

Figure 1. IMD promotes HepG2 cell proliferation in a dose-dependent manner ( ${ }^{*} \mathrm{P}<0.05$, compared with the control group). IMD, intermedin.

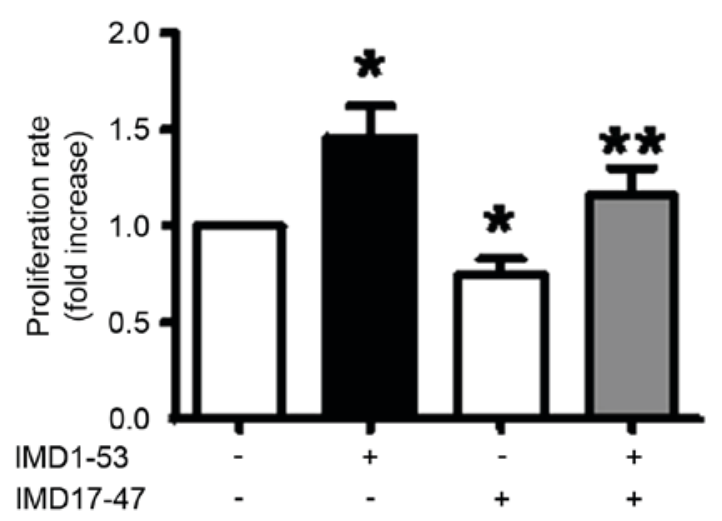

Figure 2. IMD receptor antagonists inhibit the promotion effect of IMD on HepG 2 cell proliferation $\left({ }^{*} \mathrm{P}<0.05\right.$, vs. the control group; ${ }^{* *} \mathrm{P}<0.05$ vs. IMD treatment group). IMD, intermedin.

for $30 \mathrm{sec}$ at $58^{\circ} \mathrm{C}$, extension for $30 \mathrm{sec}$ at $72^{\circ} \mathrm{C}$ then extension for $5 \mathrm{~min}$ at $72^{\circ} \mathrm{C}$, with a total of 40 cycles. Stratagene Mx3000p software (Stratagene; Agilent Technologies, Inc., Santa Clara, CA, USA) was used for analysis. The $2^{-\Delta \Delta C q}$ method was used to quantify expression levels (13). Primer sequences were as follows: Human $c$-Myc upstream, 5'-TGC TCCATGAGGAGACACC-3' and downstream, 5'-CTTTTC CACAGAAACAAC ATCG-3'; human cyclin D1 upstream, 5'-GAAGATCGTCGCCACCTG-3' and downstream, 5'-GAC CTCCTCCTCGCACTTCT-3'; human $\beta$-actin upstream, 5'-ATCTGGCACCACACCTTC-3' and downstream, 5'-AGC CAGGTCCAGACGCA-3' (Shanghai, China Solarbio Biological Technology Co., Ltd.). The RT-qPCR protocol was repeated 5 times.

Luciferase activity measurement. HepG2 cells in the logarithmic growth phase were seeded on 12 -well plates at $1 \times 10^{6}$ cells/well, then placed in a $5 \% \mathrm{CO}_{2}$ incubator at $37^{\circ} \mathrm{C}$ for $12 \mathrm{~h}$, and each well was transfected with $0.5 \mu \mathrm{g}$ various plasmids (using TOPFlash as the reporter plasmid, FOPFlash as a negative control and pRL-TK as an internal control) using jetPEI ${ }^{\circledR}$ reagent, and then incubated at $37^{\circ} \mathrm{C}$ for $24 \mathrm{~h}$. The luciferase activity was measured with the Dual-Luciferase ${ }^{\mathrm{TM}}$ Reporter Assay System (Promega Corporation), according to the manufacturer's protocol (14). 
A

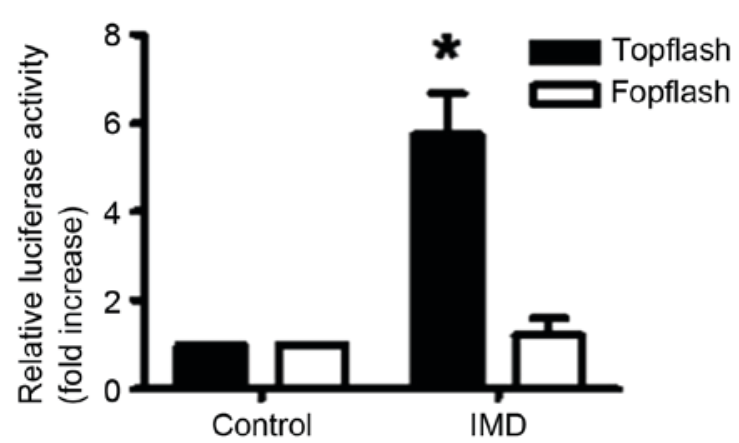

B

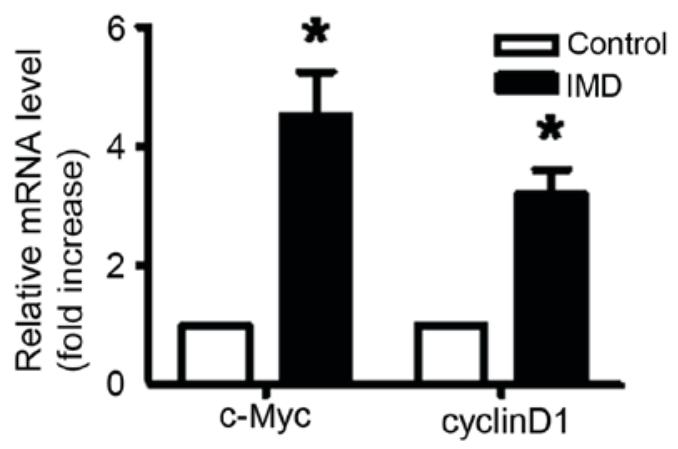

Figure 3. IMD activates the classical Wnt signaling pathway. (A) TOPflash/FOPflash luciferase activity detection. (B) The mRNA expression levels of the downstream target genes $c-M y c$ and cyclin $D 1\left({ }^{*} \mathrm{P}<0.05\right.$, vs. the control group). IMD, intermedin.

Statistical analysis. All results are presented as the mean \pm standard error of the mean. GraphPadPrism5.0 $0^{\circledR}$ software (GraphPad Software, Inc., La Jolla, CA, USA) was used for analysis and creating the data graphs. A one-way analysis of variance was conducted for multi-group comparison, and the Student-Newman-Keuls method was used for post-hoc analysis and comparisons between the groups. Student's t-test was used to compare the results between groups. $\mathrm{P}<0.05$ was considered to indicate a significantly different difference.

\section{Results}

IMD induces HepG2 cell proliferation in a dose-dependent manner. The present study explored the direct effect of IMD on HepG 2 cell proliferation. The results of the CCK-8 test demonstrated that the administration of 5-100 nM IMD for 48 h significantly promoted HepG2 cell proliferation (Fig. 1; $\mathrm{P}<0.05$, compared with the control).

IMD promotes HepG2 cell proliferation in a dose-dependent manner. Additional analysis revealed that treatment with 100 nM IMD17-47 (competitive antagonist of the IMD receptor) significantly inhibited the promotion effect of $10 \mathrm{nM}$ IMD on cell proliferation $(\mathrm{P}<0.05)$. Furthermore, IMD was observed to promote HepG 2 cell proliferation in a dose-dependent manner, and exhibited a receptor-dependent manner (Fig. 2).

IMD activates the classical Wnt signaling pathway in HepG2 cells. The possible underlying mechanisms associated with IMD-promoted HepG2 cell proliferation were also investigated. The Wnt signaling pathway serves an important role in tumor cell proliferation. TOPflash was used as a reporter plasmid, FOPflash was used as the negative control, and a thymidine kinase promoter-Renilla luciferase reporter plasmid was used as the internal reference control. Subsequent to transfection for $6 \mathrm{~h}$ and treatment with $10 \mathrm{nM}$ IMD for $24 \mathrm{~h}$, a dual luciferase activity assay was conducted. The results demonstrated that the TOPflash/FOPflash ratio following IMD stimulation was significantly higher compared with in the control group $(\mathrm{P}<0.05$; Fig. $3 \mathrm{~A})$. The mRNA levels of the downstream target genes $c-M y c$ and $c y c l i n D l$ were identified to be significantly increased $(\mathrm{P}<0.05$; Fig. $3 \mathrm{~B})$, suggesting that

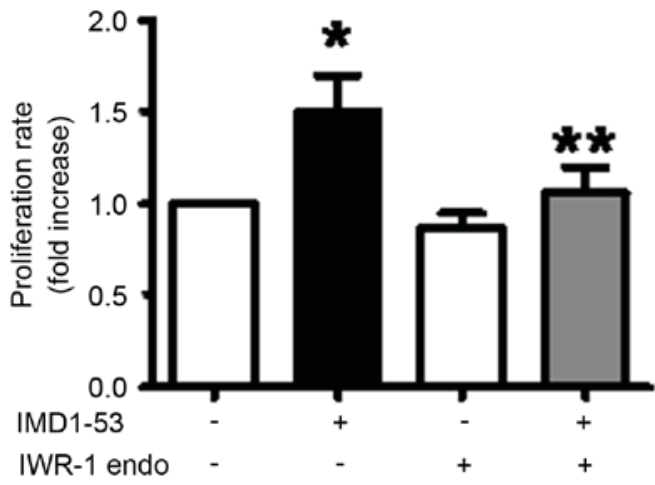

Figure 4. The Wnt signaling pathway inhibitor IWR-1-endo inhibits the promotion effect of IMD on HepG2 cell proliferation ( ${ }^{*} \mathrm{P}<0.05$, vs. the control group; ${ }^{* *} \mathrm{P}<0.05$, vs. the IMD treatment group). IMD, intermedin.

the classical Wnt signaling pathway was activated following IMD stimulation, and that specific transcriptional activity was significantly enhanced $(\mathrm{P}<0.05$; Fig. 3$)$.

IWR-1-endo is able to partially inhibit IMD-induced HepG2 cell proliferation. Pre-treatment with $25 \mu \mathrm{M}$ IWR-1-endo for 1 h significantly inhibited $10 \mathrm{nM}$ IMD-induced HepG2 cell proliferation $(\mathrm{P}<0.05$, compared with the control). Therefore, IMD may promote HepG2 cell proliferation via the Wnt signaling pathway (Fig. 4).

\section{Discussion}

The results of the present study have indicated that IMD is able promote HepG2 cell proliferation via the classical Wnt signaling pathway, according to the data that suggest the following: IMD treatment may directly induce HepG2 cell proliferation; IMD17-47 may block HepG2 cell proliferation; IMD may activate the classical Wnt signaling pathway transcriptional activity and affect downstream target gene mRNA expression levels; blocking the Wnt signaling pathway may inhibit IMD-induced HepG2 cell proliferation.

IMD is a member of the CGRP superfamily, which exhibits $\sim 30 \%$ similarity with the amino acid structure of adrenomedullin (AM), and is therefore also known as 
AM2 (7). Its precursor consists of 148 amino acid residues with multiple protease cleavage sites, and may be cut into three active fragments: IMD 1-47; IMD 8-47; IMD1-53 (15). CGRP may serve its role through binding with calcitonin receptor like receptors/receptor activity modifying protein receptor complexes (RAMPs) (16). CGRP primarily acts on RAMP1, AM principally acts on RAMP2/3 and IMD non-selectively acts on RAMP1/2/3; therefore, IMD may have a wider range of biological effects (8). A number of studies have investigated the effect of IMD on homeostasis regulation, hypertension, myocardial ischemia, heart failure and renal failure $(15,17,18)$. Although previous studies have revealed that the expression of IMD in pancreatic cancer and breast cancer was higher than the control group $(19,20)$, the effect of IMD in tumors, particularly in the occurrence and development of liver cancer, remains unclear. The results of the present study demonstrated that IMD may promote HepG2 cell proliferation (Fig. 1), and this effect is achieved through receptor-dependence (Fig. 2). The autocrine hypothesis proposed that numerous tumor cells may react with self-secreted growth factors, such as basic fibroblast growth factor, and thereby escape from growth inhibition $(21,22)$. The present study also observed that the IMD receptor blocker IMD17-47 can still inhibit the proliferation of HepG2 cells without exogenous IMD stimulation (Fig. 2), indicating that HepG2 cell may express and secrete IMD. This result is concordant with the data obtained by Guo et al (23).

The Wnt signaling pathway has an important role in the proliferation of tumor cells. Activation of the classical Wnt signaling pathway is dependent on the abnormal accumulation of $\beta$-catenin in the cytoplasm, which then enters the nucleus and binds with TCF/LEF to form transcription factor complexes, these complexes then regulate the expression of various downstream genes, including cyclin DI and $c$-Myc $(24,25)$. Previous studies have demonstrated that $30-40 \%$ of liver cancer cases also exhibit a disorder of the Wnt signaling pathway or a $\beta$-catenin gene mutation; $\beta$-catenin expression may be observed in the cytoplasm and nucleus of $62-70 \%$ of liver cancer cells, and has been observed to be marked in poorly differentiated HCC cell nuclei (26-28). $c-M y c$ is the first discovered downstream target gene of the $\beta$-catenin/TCF complex, and c-Myc serves an important role in various biological process, including cell apoptosis, proliferation, metabolism, DNA repair and angiogenesis (29). The cyclin Dl gene is an additional direct target gene of the $\beta$-catenin/TCF pathway; sustained high expression levels of cyclin D1 may cause cells to remain in the $\mathrm{S}$ phase of growth, resulting in excessive proliferation and eventual malignant transformation (30). In the present study, the results of the TOPflash/FOPflash luciferase assay indicated that IMD may enhance the transcriptional activity of the $\beta$-catenin/TCF complex; the expression of the Wnt downstream genes cyclin DI and $c-M y c$ were also significantly upregulated, suggesting that IMD may activate the Wnt signaling pathway, thus promoting HepG2 cell proliferation.

In conclusion, the present study demonstrated that, as a member of the CGRP superfamily, IMD binds with receptor, and then activates the Wnt signaling pathway, thus, it serves a role in promoting the proliferation of liver cancer cells, which presents a novel strategy for the treatment of liver cancer. In addition, IMD antagonists may be used as a potential anti-liver cancer agent.

\section{Acknowledgements}

The present study was supported by the Project of Shenyang Municipal Science and Technology Bureau (grant no. F12-93-9-56).

\section{Competing interests}

The authors declare that they have no competing interests.

\section{References}

1. Tang B, Liang X, Tang F, Zhang J, Zeng S, Jin S, Zhou L, Kudo Y and Qi G: Expression of USP22 and Survivin is an indicator of malignant behavior in hepatocellular carcinoma. Int J Oncol 47: 2208-2216, 2015.

2. Zhuang PH, Xu L, Gao L, Lu W, Ruan LT and Yang J: Correlations of microvascular blood flow of contrast-enhanced ultrasound and $\mathrm{HGF} / \mathrm{c}-\mathrm{Met}$ signaling pathway with clinicopathological features and prognosis of patients with hepatocellular carcinoma. Onco Targets Ther 10: 847-857, 2017.

3. Dai L, Peng XX, Tan EM and Zhang JY: Tumor-associated antigen CAPER $\alpha$ and microvessel density in hepatocellular carcinoma. Oncotarget 7: 16985-16995, 2016.

4. Bozkaya G, Korhan P, Cokakli M, Erdal E, Sağol O, Karademir S, Korch C and Atabey N: Cooperative interaction of MUC1 with the HGF/c-Met pathway during hepatocarcinogenesis. Mol Cancer 11: 64, 2012.

5. Whittaker S, Marais R and Zhu AX: The role of signaling pathways in the development and treatment of hepatocellular carcinoma. Oncogene 29: 4989-5005, 2010.

6. Yang C: Review on nutrition function of bioactive pephides. Food Science 24: 153-154, 2003.

7. Holmes D, Campbell M, Harbinson M and Bell D: Protective effects of intermedin on cardiovascular, pulmonary and renal diseases: Comparison with adrenomedullin and CGRP. Curr Protein Pept Sci 14: 294-329, 2013.

8. Takei Y, Inoue K, Ogoshi M, Kawahara T, Bannai H and Miyano S: Identification of novel adrenomedullin in mammals: A potent cardiovascular and renal regulator. FEBS Lett 556: 53-58, 2004.

9. Morimoto R, Satoh F, Murakami O, Hirose T, Totsune K, Imai Y, Arai Y, Suzuki T, Sasano H, Ito S and Takahashi K: Expression of adrenomedullin 2/intermedin in human adrenal tumors and attached non-neoplastic adrenal tissues. J Endocrinol 198: $175-183,2008$

10. Hikosaka T, Tsuruda T, Nagata S, Kuwasako K, Tsuchiya K, Hoshiko S, Inatsu H, Chijiiwa K and Kitamura K: Adrenomedullin production is increased in colorectal adenocarcinomas; its relation to matrix metalloproteinase-9. Peptides 32: 1825-1831, 2011.

11. Smith RS Jr, Gao L, Bledsoe G, Chao L and Chao J: Intermedin is a new angiogenic growth factor. Am J Physiol Heart Circ Physiol 297: H1040-H1047, 2009.

12. Xu Y, Pang X, Dong M, Wen F and Zhang Y: Nesfatin-1 inhibits ovarian epithelial carcinoma cell proliferation in vitro. Biochem Biophys Res Commun 440: 467-472, 2013.

13. Livak KJ and Schmittgen TD: Analysis of relative gene expression data using real-time quantitative PCR and the 2(-Delta Delta C(T)) method. Methods 25: 402-408, 2001.

14. Zhang Y, Zhang S, Shang H, Pang X and Zhao Y: Basic fibroblast growth factor upregulates adrenomedullin expression in ovarian epithelial carcinoma cells via JNK-AP-1 pathway. Regul Pept 157: 44-50, 2009.

15. Bell D and McDermott BJ: Intermedin (adrenomedullin-2): A novel counter-regulatory peptide in the cardiovascular and renal systems. Br J Pharmacol 153 (Suppl 1): S247-S262, 2008.

16. Roh J, Chang CL, Bhalla A, Klein C and Hsu SY: Intermedin is a calcitonin/calcitonin gene-related peptide family peptide acting through the calcitonin receptor-like receptor/receptor activity-modifying protein receptor complexes. J Biol Chem 279: 7264-7274, 2004.

17. Dong F, Taylor MM, Samson WK and Ren J: Intermedin (adrenomedullin-2. enhances cardiac contractile function via a protein kinase $\mathrm{C}$ - and protein kinase $\mathrm{A}$-dependent pathway in murine ventricular myocytes. J Appl Physiol (1985) 101: 778-784, 2006. 
18. Ren H, Ren H, Li X, Yu D, Mu S, Chen Z and Fu Q: Effects of intermedin on proliferation, apoptosis and the expression of OPG/RANKL/M-CSF in the MC3T3-E1 osteoblast cell line. Mol Med Rep 12: 6711-6717, 2015.

19. Hollander LL, Guo X, Salem RR and Cha CH: The novel tumor angiogenic factor, adrenomedullin-2, predicts survival in pancreatic adenocarcinoma. J Surg Res 197: 219-224, 2015.

20. Lu YM, Zhong JB, Wang HY, Yu XF and Li ZQ: The prognostic value of intermedin in patients with breast cancer. Dis Markers 2015: 862158, 2015.

21. Billottet C, Janji B, Thiery JP and Jouanneau J: Rapid tumor development and potent vascularization are independent events in carcinoma producing FGF-1 or FGF-2. Oncogene 21: 8128-8139, 2002.

22. Di Blasio AM, Cremonesi L, Viganó P, Ferrari M, Gospodarowicz D, Vignali $\mathrm{M}$ and Jaffe RB: Basic fibroblast growth factor and its receptor messenger ribonucleic acids are expressed in human ovarian epithelial neoplasms. Am J Obstet Gynecol 169: 1517-1523, 1993.

23. Guo X, Schmitz JC, Kenney BC, Uchio EM, Kulkarni S and Cha $\mathrm{CH}$ : Intermedin is overexpressed in hepatocellular carcinoma and regulates cell proliferation and survival. Cancer Sci 103: 1474-1480, 2012.
24. Moon RT, Bowerman B, Boutros M and Perrimon N: The promise and perils of Wnt signaling through beta-catenin. Science 296: 1644-1646, 2002.

25. Clevers H: Wnt/beta-catenin signaling in development and disease. Cell 127: 469-480, 2006

26. Wong CM, Fan ST and Ng IO: Beta-catenin mutation and overexpression in hepatocellular carcinoma: Clinicopathologic and prognostic significance. Cancer 92: 136-145, 2001.

27. Devereux TR, Stern MC, Flake GP, Yu MC, Zhang ZQ, London SJ and Taylor JA: CTNNB1 mutations and beta-catenin protein accumulation in human hepatocellular carcinomas associated with high exposure to aflatoxin B1. Mol Carcinog 31: 68-73, 2001.

28. Hsu HC, Jeng YM, Mao TL, Chu JS, Lai PL and Peng SY: Beta-catenin mutations are associated with a subset of low-stage hepatocellular carcinoma negative for hepatitis B virus and with favorable prognosis. Am J Pathol 157: 763-770, 2000.

29. Bienz $M$ and Clevers H: Linking colorectal cancer to Wnt signaling. Cell 103: 311-320, 2000.

30. Tetsu $\mathrm{O}$ and McCormick F: Beta-catenin regulates expression of cyclin D1 in colon carcinoma cells. Nature 398: 422-426, 1999. 